\title{
CERTAIN DISTINCT ADVANCES IN THE ANALYTICAL CHEMISTRY OF RECENT YEARS.'
}

BY ALREKT I. PRESCOTt.

$\mathrm{O}$

F the important gains made by the present generation of chemists let us acknowledge ( $f$ ) the resolute attempt to find out the composition of matter as a whole in any and all of its mixtures of whatever source.

Analytical workers have undertaken to resolve the complex mass and account for all its contents. It has been their ambition to identify and determine existing molecules of every sort within a given mixture, while synthetical workers have sought to reach the constitution of the molecules themselves. The task of complete analysis has been entered upon, that called "proximate" as well as that called "ultimate." There have been good investigations that have taken "extractive matter" and "empyreumatic matter" and "bituminous matter" and other undetermined residues as subjects for the beginning of chemical work rather than the end of it. The task of the complete analysis of matter in its every possible portion is a task that has been recognized and entered upon as a necessity of chemical advancement.

I do not by any means infer that the determination of distinct compounds is the result of analytical chemistry alone, as but one of the divisions of the science. On the contrary I would emphasize the dependence of the analyst upon the entire body of chemical learning. He is limited by this dependence even for the identification and estimation of distinct bodies without going into the make-up of molecules. Analysis is or ought to be a certain function of the whole body of chemistry, not a part of the body which could live if separated. An analyst can not well be less than a whole chemist, and though his ends be single in direction, they are not indifferent to the powers common to all cinemical insight.

The analytic method began to yield large returns in the last century. When Black made more exact qualitative examination of fixed air he began to uncover that chain of underlying truth laid hold of by Priestley and fairly dislodged by Lavoisier and other contemporaries. In the first half of this century the

1 Read before the World's Congress of Chemists, August 22, 1893 . 
enormous analytical detail instituted by Berzelius extended the very foundations of physical science. And in the present generation the analyses of biological chemists and industrial chemists of many and various purposes have been very influential factors in the support of great principles of chemical truth.

Again, the courage of analytical effort in recent years has been seen especially

(2) In the elaboration of methods for the isolation of carbon compounds, both natural and artificial. "Proximate organic analysis" is not so greatly at a discount as it was twenty years ago. Research has been devoted to the estimation of organic compounds, unbroken and unaltered. It has been a common necessity to effect determinations truly "proximate," in the definition of this inadequate word. There have been pointed inquiries from the biologist often, from the metallurgist at times, from the theoretical chemist not seldom, what is the chemical character of this body as its exists just before its analysis? Since Dragendorff devised ways of plant analysis, and HoppeSeyler collected methods of physiological analysis, thousands of contributions have enriched the resources of the organic analyst and thousands of workers are now in like endeavor. Chemical literature is thickly strewn with directions for analysis to the end of the identification of the integral molecule, representing matter in its living state, if such a figure of speech may be used. This is indeed the special task of analytical research, although the terms of analysis are also given to operations that accompany synthetic work, to wit:

(3) In studies of the molecular structure of bodies produced by nature, bodies mineral, vegetable, and animal, as well as those of artificial production. To classify analytical work strictly by definition, which, however, I have no desire to do, all the studies of molecular constitution come within the range of analytical inquiry. But even under customary classification of chemical labor, it will be observed that certain instruments of observation early used by analytical chemists have since been found most effective in studies of molecular structure even for what is termed the configuration of the molecule. Especially, therefore, 
(4) In the employment of physical methods of inspection, whereby molecular change is avolded, important advances have been made in the analyes of recent vears.

First of all through the several responses of the molecule to light, under more exact observation, the clearest of identifications have been obtained. Optical methods have multiplied and become more exact. We ate however, only in the beginning of their adaptation to analysis. Studies of geometric isomerism have shown the analyst how rich in results the polarimeter may become. Next to this, probably. stands the refractometer in its value as a means of recognition in analysis. Then the use of the spectroscope for studies of absorption by transparent bodies has already done admirable service to analysis, both organic and inorganic. New responses of matter to heat have heen brought under observation. In qualitative deternination, as in the finding of the molecular mass. the freezing point and the effect on solidifying points of solvents are in question as well as the melting points and boiling points. The chemical world is alive with interest in the advances of the new physical chemistry. To these adrances no one is and is to be more inclebted than the analyst. Solubility itseif, the great common factor of analytical operation, is under inestigations in which the analyst has the keenest interest. The feebler influences of allhesion, too often orerlooked, causing waste in cluantitative separations and putting limits upon the best of our results for analytical recovery, these, with the phenonena of capillarity, are well wnder investigation. The rery checks of control analyses serve as data for studies in molecular physics.

It is not possible for me to group togetiser in classes near all the ways of advance in recent analytical chenistry, and I will but specify once more how this adwance appears

(5) In the reciprocal benefits of scientific research and of technical skill. We see this in the work of experts, those in biological and pathological analysis, sanitary and forensic analysis, industrial and conmercial analysis, agricultural and metallurgical analysis. Chemical literature curing the last ten years shows how promptly discoveries like those of Iinil Fischer in the sugar group, or those of Ladenburg upon hydrolysis of 
alkaloids, those of Gladstone on refraction equivalents, or those of Baeyer upon the phthaleins, become well reduced to practice in the operations of analytical work. The simple volumetric estimations of acid and alkali are expanded in ten-fold application in thousands of analytical laboratories by means of varied indicators from the color discoveries of coal tar chemists such as Otto Witt. Analysis bows its acknowledgment of indebtedness to synthetic research. The interests of the section of analytical chemistry are all interwoven with the interests of all the sections of this congress. The analytical chemist will be a good listener to all the papers in the rich and varied repertory of the week before us.

\section{ON THE ARTIFICIAL PRODUCTION OF PETROLEUM.}

By DR. C. ENGLer.

CIENTISTS have discussed very often in the last few years $\int$ the question in which way petroleum, this source of wealth, with its special scientific interest for this country, was formed by nature. According to one theory it is generated from inorganic materials. Sokoloff thinks, that petroleum was produced during the period of the formation of our planet out of cosmical hydrocarbons, which in the beginning dissolved in the soft mass, separated from it later on. Mendelejeff assumes that water entering by fissures and chasms the interior of the earth came in contact with melting carbide of iron and produced so in a simple manner oxide of iron and the hydrocarbons of petroleum. Strong objection cannot be made to these two theories from the chemical standpoint; but the composition of the different kinds of petroleum is against them, and geology considers them not free from objections.

For a series of years the idea that petroleum was produced from the remains of plants by a kind of a distillation process, was most generally adopted, especially by chemists. Chemical and geological reasons are against this theory. From the chemical standpoint it seems quite impossible that the substance of the plants could be split up by distillation into petroleum without

1 Read before the World's Congress of Chemists, August 23, 1893. 